\title{
SISTEM PENGOLAHAN DATA NILAI BERBASIS WEB PADA SEKOLAH MENENGAH PERTAMA (SMP) KAREL SADSUITUBUN LANGGUR
}

\author{
Aziz Setyawan Hidayat ${ }^{1}$ \\ Teknik Komputer PSDKU \\ Universitas Bina Sarana Informatika Tegal \\ aziz.aiz@bsi.ac.id \\ Wandy Ubleeuw ${ }^{2}$ \\ Sistem Informasi, STIMIK Nusa Mandiri Jakarta \\ 1d.apradis@gmail.com
}

\author{
Ahmad Fauzi ${ }^{3}$ \\ Sistem Informasi Akuntansi, \\ Universitas Bina Sarana Informatika \\ ahmad.afz@bsi.ac.id
}

Pas Mahyu Akhirianto ${ }^{4}$

Teknik Komputer PSDKU, Universitas Bina Sarana Informatika Tegal Pas.pma@bsi.ac.id

\begin{abstract}
Abstrak - Sekolah sebagai salah satu lembaga pendidikan yang berfungsi untuk melaksanakan proses belajar mengajar diharapkan bisa mengikuti perkembangan dalam bidang teknologi informasi. SMP Karel Sadsuitubun Langgur saat ini proses pengolahan data nilai akademiknya masih belum optimal. Penyimpanan data dan pengolahan data saat ini masih dilakukan secara konvensioanl sehingga tidak terlalu optimal. Tujuan penelitian ini adalah agar mengetahui cara pengolahan data nilai yang sedang berjalan, membangun sistem pengolahan data nilai berbasis web, dan mengimplementasinya. Metode penelitian yang digunakan adalah observasi, wawancara, dan studi pustaka yang berhubungan dengan kasus yang terjadi. Sistem Pengolahan data nilai ini menggunakan model pengembangan watterfall dan dibangun menggunakan bahasa pemograman PHP (Personal Home Page) dan untuk perancangan basis data menggunakan Entity Relationship Diagram (ERD). Software yang digunakan adalah Xampp yang digunakan untuk webserver, PHPMYSQL sebagai database, serta Adobe Dreamweaver CS6 sebagai editor $\underline{P H P}$. Dengan adanya website ini maka akan membantu pengolahan data nilai para siswa yang di lakukan oleh guru agar lebih efisien. Kata Kunci : Data, Nilai, Web, Watterfall
\end{abstract}

\section{PENDAHULUAN}

Seiring dengan perkembangan teknologi informasi yang semakin maju memberikan dampak kontribusi yang nyata bagi suatu lembaga atau organisasi. Teknologi menjadi suatu hal yang dibutuhkan oleh semua orang, karena dengan adanya teknologi informasi seseorang akan lebih cepat mengetahui informasi yang ada disekitarnya.

Nugraha dkk dalam jurnalnya (2018:21) mengemukakan bahwa "Agar efisiensi dan efektifitas dapat tercapai, maka diperlukan suatu pengelolaan yang baik dan benar terhadap teknologi informasi yang terdapat dalam organisasi/instansi."

\section{Demikian pula dengan SMP Karel Sadsuitubun} Langgur yang merupakan salah satu sekolah swasta yang terdapat di kota Langgur kabupaten Maluku Tenggara wilayah provinsi Maluku. Saat ini proses pengolahan data nilai akademiknya masih belum optimal. Penyimpanan data dan pengolahan data saat ini masih menggunakan Ms Excel, dan belum adanya sistem informasi berbasis web yang terintergrasi dengan database. Menyebabkan guru, siswa dan orang tua siswa harus datang ke sekolah terlebih dahulu untuk mendapatkan informasi akademik.

Sistem informasi yang dibangun ini akan berbasis web sehingga diharapkan dapat membantu guru, siswa, serta orang tua untuk mengakses informasi data nilai melalui internet dan dapat memperoleh informasi tanpa perlu pergi ke sekolah atau menunggu hingga akhir semester untuk pembagian buku raport, sehingga cukup dengan mengakses website sekolah dan melihat informasi data nilai siswa.

Dari pernyataan di atas maka dapat di simpulkan bahwa penyampaian informasi tentang nilai siswa pada SMP Karel Sadsuitubun Langgur saat ini belum tersampaikan kepada orang tua siswa secara baik. Oleh sebab itu perlu dilakukan penambahan sarana penyebaran informasi tentang nilai siswa, salah satunya menggunakan sarana akses internet yang diwadahi dalam sebuah website.

\section{KAJIAN LITERATUR}

\section{Definisi Sistem}

Menurut Pratama ( 2014:7) "sistem didefinisikan sebagai sekumpulan prosedur yang saling berkaitan dan saling terhubung untuk melakukan suatu tugas bersamasama". Secara garis besar, sebuah sistem informasi terdiri dari tiga komponen utama. Ketiga komponen tersebut mencakup software, hardware, dan brainware. Ketiga komponen ini saling berkaitan satu sama lain. 


\section{Informasi}

Menurut Pratama (2014:9) "informasi merupakan hasil pengolahan data dari satu atau berbagai sumber, yang kemudian diolah, sehingga memberikan nilai, arti dan manfaat". Pada proses pengolahan data, untuk dapat menghasilkan informasi, juga dilakukan proses verifikasi secara akurat, spesifik dan tepat waktu. Hal ini penting agar informasi dapat memberikan nilai dan pemahaman kepada pengguna.

\section{Pengolahan Data}

Menurut Syaripudin dan Evicenna (2015:128) "Pengolahan Data adalah manipulasi dari data kedalam bentuk yang lebih berguna dan lebih berarti dari suatu kejadian berupa informasi”. Berdasarkan kutipan diatas dapat disimpulkan bahwa pengolahan data adalah kecepatan, daya tahan manipulasi dari data yang kesebergunaannya lebih berarti dari kejadian berupa informasi.

\section{Nilai Siswa}

Pengolahan nilai siswa merupakan salah satu bagian dari kegiatan belajar mengajar disekolah. Yang terpenting dalam belajar mengajar yang merupakan alat ukur prestasi siswa. Dengan adanya pengolahan dan manajemen yang baik pengolahan data nilai akan lebih mudah, cepat dan akurat.

\section{HTML (Hyper Text markup Language)}

Menurut Saputra (2013:1) "HTML merupakan singkatan dari Hyper Text Language. HTML digunakan untuk menampilkan dan mengelolah tampilan pada halaman website". HTML digunakan untuk menampilkan berbagai informasi didalam sebuah penjelajah web internet dan formating hypertext sederhana yang ditulis ke dalam berkas format ASCII agar dapat menghasilkan tampilan wujud yang terintegrasi.

\section{PHP (Personal Home Page)}

Menurut Madcom (2016:2) "PHP (Hypertext Preprocessor) adalah bahasa script yang dapat ditanamkan atau disisipkan ke dalam HTML". PHP banyak dipakai untuk membuat program situs web dinamis. PHP sering juga digunakan untuk membangun sebuah CMS. PHP adalah bahasa pemrograman script server-side yang didesain untuk pengembangan web. Disebut bahasa pemrograman server side karena PHP diproses pada komputer server. Hal ini berbeda dibandingkan dengan bahasa pemrograman client-side seperti JavaScript yang diproses pada web browser (client).

\section{CSS (Cascanding Style Sheet)}

Menurut Saputra (2013:27) CSS yang merupakan singakatan dari cascading style sheet merupakan bahasa pemrograman web yang didesain khusus untuk mengendalikan dan membangun berbagai komponen dalam web sehingga lebih rapih, terstruktur, dan seragam.

\section{Java Script}

Menurut Hidayatullah \& Kawistara (2015:422) JavaScript ialah suatu bahasa scripting yang digunakan sebagai fungsionalitas dalam membuat suatu web".

Kode javascript biasanya disisipkan diantara kode-kode Hyper Text Markup Language (HTML), diawali dengan tag $<$ script language $=$ "javascript" $>$ dan diakhiri dengan $</$ script $>$. Setiap baris kode javascript dipisahkan baris baru atau bisa juga titik koma (;). Javascript bersifat case sensitive, artinya huruf kecil dan huruf besar adalah berbeda.

Javascript dapat mendeteksi event atau kejadiankejadian yang terjadi dihalaman web, kemudian melakukan suatu proses jika terdeteksi suatu event. Event di web bisa macam-macam seperti klik, double klik, menggerakkan mouse, bila pointer mouse berada diatas suatu objek Hyper Text Markup Language (HTML) dan sebagainya.

Selain dapat mendeteksi event dan memproses suatu fungsi, javascript juga dapat menampilkan dialog box, ada beberapa dialog box yang dapat digunakan seperti: Alert, confirm dan prompt. Alret digunakan sebagai pesan atau informasi ketika suatu kondisi terpenuhi. Confirm merupakan pesan konfirmasi yang terdiri dari dua tombol yaitu tombol Yes dan No. Sedangkan prompt merupakan input box yang dapat digunakan untuk memasukkan data yang akan diproses. 9. Pengertian Basis Data (Database)

Menurut Pahlevi (2013:1) "Basis data adalah sekumpulan data yang saling berhubungan secara logis beserta deskripsinya, yang digunakan secara bersamasama dan dirancang untuk memenuhi kebutuhan informasi disuatu tempat."

Sedangkan menurut Rosa dan Shalahuddin (2013:43) "sistem basis data adalah sistem terkomputerisasi yang tujuan utamanya adalah memelihara data yang sudah diolah atau informasi dan membuat informasi tersedia saat dibutuhkan".

\section{MySQL (My Structured Query Language)}

Menurut Hidayatullah \& Kawistara (2015:180) MySQL adalah salah satu aplikasi DBMS yang sudah sangat banyak digunakan oleh para pemrograman aplikasi web. Contoh DBMS lainnya adalah : PostgreSQL (freeware), SQL Server, MS Access dari Microsoft, DB2 dari IBM, Oracle dan Oracle Corp, Dbase, FoxPro dan sebagainya.

Kelebihan dari MySQL adalah gratis, handal, selalu di-update dan banyak forum yang memfasilitasi para pengguna jika memiliki kendala. MySQL juga menjadi DBMS yang sering dibundling dengan web server sehingga proses instalasinya jadi lebih mudah.

\section{Pengertian XAMPP}

Menurut Raharjo (2015:25) "XAMPP adalah kompilasi software yang membungkus Apache HTTP server, MySQL, PHP dan Perl". Dengan menggunakan XAMP, instalasi paket software yang dibutuhkan untuk proses pengembangan web (Apache HTTP server, MySQL dan PHP) dapat dilakukan dengan sangat 
mudah, tanpa harus dilakukan secara terpisah (sendirisendiri) seperti yang telah dibahas pada sub bab sebelumnya.

\section{Entity Relationship Diagram (ERD)}

Menurut Sukamto \& Shalahuddin (2014:53) Entity Relationship Diagram (ERD) adalah bentuk paling awal dalam melakukan perancangan basis data relasional. Jika menggunakan OODBMS maka perancangan Entity Relationship Diagram (ERD) tidak perlu dilakukan.

Menurut Priyadi (2014:5) kardinalitas merupakan batasan dari banyaknya hubungan yang dapat dilakukan oleh suatu himpunan entitas dalam melakukan relasi dengan himpunan entita lainnya. Variasi kemungkinan untuk melakukan relasi yang dimiliki oleh kardinalitas terdiri dari 4 macam, yaitu :
a. Satu ke satu $(1: 1)$
b. Satu ke banyak

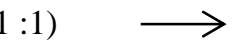
c. Banyak ke satu
d. Banyak ke banyak

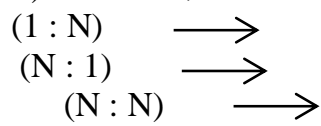
$(\mathrm{N}: \mathrm{N})$

Cara untuk menyederhanakan konsep kardinalitas pada buku ini, penerapan kasusnya dilakukan pada dua himpunan entitas saja, yaitu himpunan entitas A dan entitas B yang masing-masing himpunan terdiri dari 3 entitas sebagai berikut :

a. Kardinalitas satu ke satu (1:1), mempunyai arti bahwa setiap satu entitas pada himpunan entitas A hanya dapat berelasi dengan satu entitas saja pada himpunan entitas B. Begitupun sebaliknya bahwa setiap satu entitas pada himpunan entitas B hanya dapat berelasi dari satu entitas saja pada himpunan entitas A.

b. Kardinalitas satu ke banyak (1:N), mempunyai arti bahwa setiap satu entitas pada himpunan entitas A hanya dapat berelasi dengan banyak entitas pada himpunan entitas B. Namun tidak demikian untuk sebaliknya bahwa beberapa entitas pada himpunan entitas B hanya dapat berelasi dengan satu entitas saja pada himpunan entitas $\mathrm{A}$.

c. Kardinalitas banyak ke satu (N:1), mempunyai arti bahwa beberapa entitas pada himpunan entitas A hanya dapat berelasi dengan satu entitas saja pada himpunan entitas B. Namun tidak demikian sebaliknya bahwa setiap satu entitas pada himpunan entitas B dapat berelasi dengan beberapa entitas pada himpunan entitas A.

Kardinalitas banyak ke banyak (N:N), mempunyai arti bahwa beberapa entitas pada himpunan entitas A hanya dapat berelasi dengan banyak entitas saja pada himpunan entitas B. Demikian juga untuk sebaliknya bahwa beberapa entitas pada himpunan entitas $\mathrm{B}$ hanya dapat berelasi dengan banyak entitas saja pada himpunan entitas A.

\section{SDLC (System Development Lifecycle)}

Model pengembangan sistem yang penulis gunakan adalah metode pengembangan sistem dengan model waterfall. Menurut Rosa dan Shalahuddin (2015:28) "Model SDLC air terjun (waterfall) sering juga disebut model sekuensial linier (sequential linier) atau alur hidup klasik (classic life cycle)". Model air terjun menyediakan pendekatan alur hidup perangkat lunak secara sekuensial atau terturut dimulai dari analisis, desain, pengodean, pengujian, dan tahap pendukung (support).

\section{a. Analisis kebutuhan perangkat Sistem}

Proses pengumpulan kebutuhan dilakukan secara intensif untuk menspesifikasikan kebutuhan perangkat lunak agar dapat dipahami perangkat lunak seperti apa yang dibutuhkan oleh user. Spesifikasi kebutuhan perangkat lunak pada tahap ini perlu untuk didokumentasikan.

\section{b. Desain}

Desain perangkat lunak adalah proses multi langkah yang fokus pada desain pembuatan program perangkat lunak, representasi antarmuka, dan prosedur pengkodean. Tahap ini mentranslasi kebutuhan perangkat lunak, dari tahap analisis kebutuhan representasi desain agar dapat diimplementasikan menjadi program pada tahap selanjutnya. Desain perangkat lunak yang dihasilkan pada tahap ini juga perlu didokumentasikan.

\section{c. Pembuatan kode program}

Desain harus ditranslasikan ke dalam program perangkat lunak. Hasil dari tahap ini adalah program komputer sesuai dengan desain yang telah dibuat pada tahap desain.

\section{d. Pengujian}

Pengujian terfokus pada perangkat lunak, dilakukan dari segi logic dan fungsional dan memastikan bahwa semua bagian sudah diuji. Hal ini dilakukan untuk meminimalisir kesalahan (error) dan memastikan keluaran yang dihasilkan sesuai yang diinginkan.

\section{e. Pendukung}

Tidak menutup kemungkinan sebuah perangkat lunak mengalami perubahan ketika sudah dikirimkan ke user. Perubahan bisa terjadi karena adanya kesalahan yang muncul dan tidak terdeteksi saat pengujian atau perangkat lunak harus beradaptasi dengan lingkungan baru. Tahap pendukung atau pemeliharaan dapat mengulangi proses pengembangan mulai dari analisis spesifikasi untuk perubahan perangkat lunak yang sudah ada, tapi tidak untuk membuat perangkat lunak baru.

\section{Unifield Modeling Language (UML)}

Menurut Rosa dan Shalahuddin (2015:133) "UML (Unifield Modeling Language) adalah salah satu standar bahasa yang banyak digunakan di dunia industri untuk mendefinisikan requirement, membuat analisis \& desain, serta menggambarkan arsitektur dalam pemrograman berorientasi objek".

\section{a. Activity Diagram}

Menurut Rosa dan Shalahuddin (2013:161) "Diagram aktivitas atau activity diagram menggambarkan workflow (aliran kerja) atau aktivitas dari sebuah sistem atau proses bisnis atau menu yang ada pada perangkat lunak". Yang perlu diperhatikan disini adalah bahwa diagram aktivitas 
menggambarkan aktivitas sistem bukan apa yang dilakukan aktor, jadi aktivitas yang dapat dilakukan oleh sistem.

b. Use Case Diagram

Menurut Rosa dan Shalahuddin (2013:155) "Use case Diagram atau diagram use case merupakan pemodelan untuk kelakuan (behavior) sistem informasi yang akan dibuat". Use case mendeskripsikan sebuah interaksi antara satu atau lebih aktor dengan sistem informasi yang akan dibuat. Secara kasar, use case digunakan untuk mengetahui fungsi apa saja yang ada di dalam sebuah sistem untuk informasi dan siapa saja yang berhak menggunakan fungsi-fungsi itu.

\section{c. Component Diagram}

Diagram komponen atau component diagram dibuat untuk menunjukan organisasi dan ketergantungan diantara kumpulan komponen dalam sebuah sistem. Diagram komponen fokus pada komponen sistem yang dibutuhkan dan ada di dalam sistem.

\section{d. Deployment Diagram}

Diagram deployment atau deployment diagram menunjukkan konfigurasi komponen dalam proses eksekusi aplikasi.

\section{Black Box Testing}

Menurut Rosa dan Shalahudin (2015:275): Black Box Testing yaitu menguji perangkat lunak dari segi spesifikasi fungsional tanpa menguji desain dan kode program. Pengujian dimaksudkan untuk mengetahui apakah fungsi-fungsi, masukan, dan keluaran dari perangkat lunak sesuai dengan spesifikasi yang dibutuhkan

\section{Adobe Dreamweaver CS6}

Menurut Sudradjat (2018:24) : Adobe Dreamweaver CS6 merupakan salah satu aplikasi popular yang digunakan untuk mendesain sekaligus melakukan pemrograman web. Adobe Dreamweaver CS6 memberikan fasilitas untuk mengedit HTML secara visual. Aplikasi ini menyertakan banyak perangkat yang berkaitan dengan pengkodean dan fitur seperti HTML, CSS, hingga JavaScript. Selain itu, aplikasi ini juga memungkinkan pengeditan JavaScript, XML, dan dokumen teks lainnya secara langsung.

\section{HASIL DAN PEMBAHASAN}

Berikut ini adalah proses sistem yang berjalan untuk pengolahan data nilai siswa di SMP Karel Sadsuitubun Langgur :

Guru masing - masing mata pelajaran bertugas mengumpulkan nilai para siswa yang terdiri dari nilai ulangan harian, nilai tugas, nilai ujian tengah semester dan nilai ujian akhir semester. Nilai - nilai yang telah dikumpulkan kemudian diolah dan dimasukan kedalam daftar nilai, yang kemudian akan diserahkan kepada para wali kelas masing - masing kelas. Wali kelas menerima rekap nilai siswa kemudian melakukan pengisian raport siswa berdasarkan rekap nilai tersebut, raport yang telah diisi kemudian dilaporkan kepada kepala sekolah untuk disetujui, setelah raport mendapatkan persetujuan dari kepala sekolah, wali kelas kemudian memberikan hasil raport tersebut kepada orangtua atau siswa.

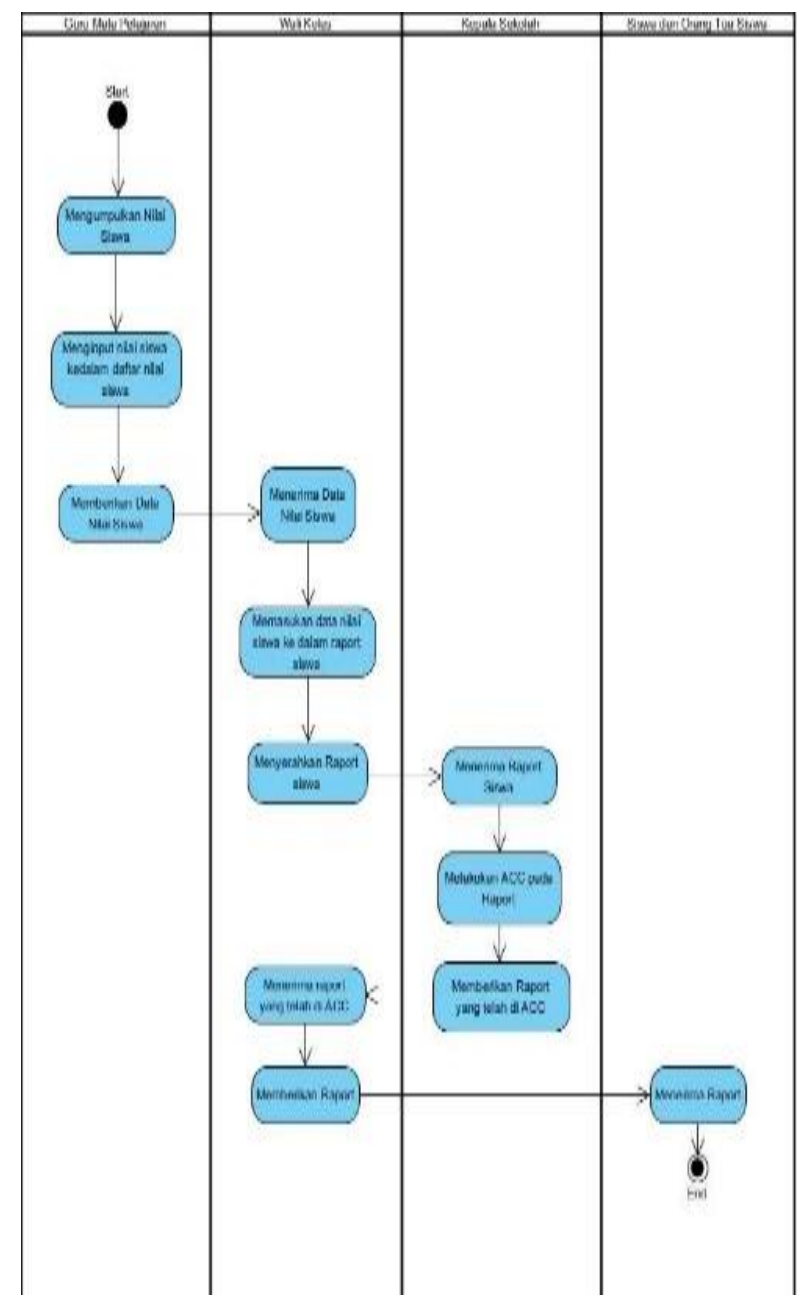

Gambar III.2. Activity Diagram Sistem Berjalan

\section{Spesifikasi Dokumen Sistem Berjalan:}

Bentuk spesifikasi dokumen-dokumen yang digunakan pada sistem berjalan, dapat dibagi menjadi 2 bagian yaitu spesifikasi bentuk dokumen masukan dan spesifikasi bentuk dokumen keluaran yang akan di jelaskan sebagai berikut.

Berikut spesifikasi kebutuhan dari sistem pengolahan data nilai siswa berbasis web.

a. Halaman siswa :

A1. Siswa dapat melakukan login dengan memasukan username dan password

A2. Siswa dapat melihat hasil nilai yang meliputi ulangan harian, nilai tugas, nilai ulangan tengah semester dan nilai ulangan akhir semester. 
A3. Siswa dapat melihat daftar guru

b. Halaman Wali Kelas :

B1. Wali kelas dapat melakukan login dengan memasukan username dan password

B2. Wali kelas dapat melihat data nilai siswa

B3. Wali kelas dapat mengelola data absensi siswa

B4. Wali kelas dapat mencetak data nilai raport siswa

c. Halaman Guru

C1. Guru dapat melakukan login dengan memasukan username dan password

C2. Guru dapat melihat kelas yang diajarkan

C3. Guru dapat mengelola data nilai siswa

d. Halaman Admin :

D1. Admin dapat login dengan memasukan username dan password

D2. Admin dapat mengelola data guru

D3. Admin dapat mengelola data siswa

D4. Admin dapat mengelola data kelas

D5. Admin dapat mengelola data wali kelas

D6. Admin dapat mengelola data mata pelajaran

D7. Admin dapat mengelola data akun

Berikut spesifikasi kebutuhan dari sistem pengolahan data nilai siswa berbasis web.

Nama Dokumen: Raport

Fungsi : Sebagai Informasi Nilai Siswa

Sumber : Wali Kelas

Tujuan : Orang Tua Siswa

Media : Kertas

Frekuensi : Setiap laporan siswa satu semester

Bentuk : Lampiran A-1

\section{Use Case Diagram}

Use case diagram digunakan untuk menggambarkan kebutuhan sistem dari sudut pandang user. Use case diagram terdiri atas beberapa obyek yaitu actor dan use case. Adapun use case diagram pada sistem informasi pengolahan data nilai siswa pada SMP Karel Sadsuitubun Langgur adalah sebagai berikut :

\section{a. Use Case Diagram Halaman Siswa}
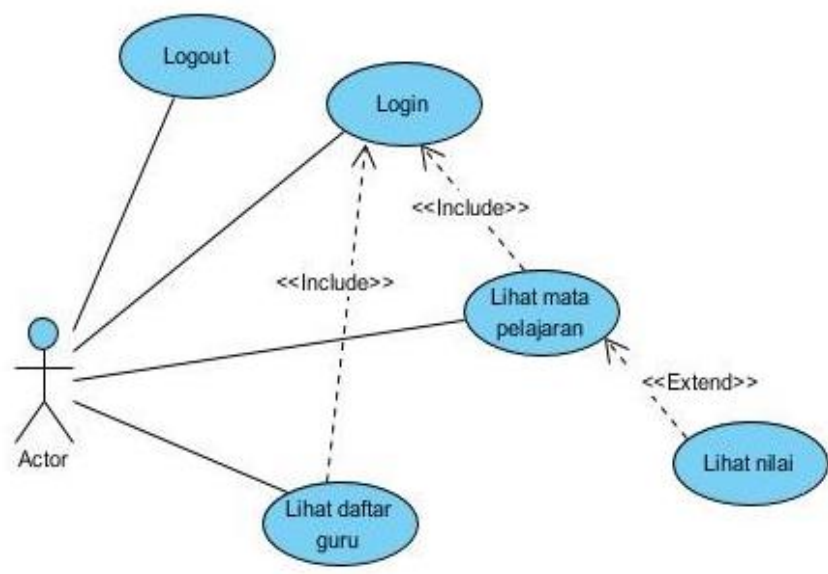

Gambar IV.1. Use Case Diagram Halaman

Siswa
Tabel IV.1.

Deskripsi Use Case Lihat Nilai Siswa Halaman Siswa

\begin{tabular}{|l|l|}
\hline Use Case Name & Melihat Nilai \\
\hline Requiretments & A2 \\
\hline Goal & Siswa dapat melihat nilai \\
\hline Pre-Conditions & Siswa sudah login \\
\hline Post-Conditions & Data nilai terlihat \\
\hline $\begin{array}{l}\text { Failed end } \\
\text { Condition }\end{array}$ & Gagal melihat nilai \\
\hline Primary Actors & Siswa \\
\hline $\begin{array}{l}\text { Main Flow / Basic } \\
\text { Path }\end{array}$ & $\begin{array}{l}\text { 1. Siswa memilih menu nilai } \\
\text { 2. Sistem menampilkan nilai }\end{array}$ \\
& 3. Siswa dapat melihat data nilai \\
\hline
\end{tabular}

\section{b. U se Case Diagram Halaman Wali Kelas}

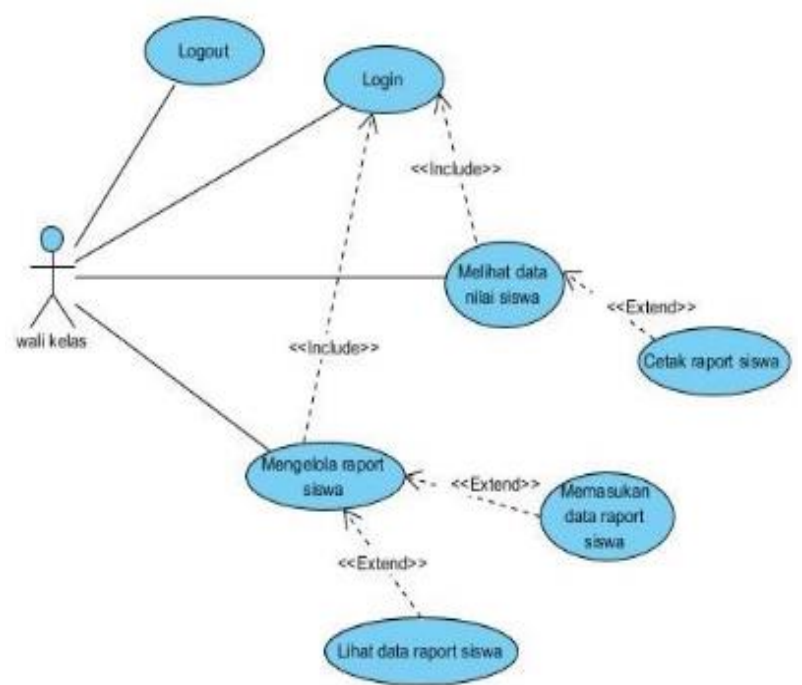

Gambar IV.2. Use Case Diagram Halaman Wali Kelas

Tabel IV.2.

Deskripsi Use Case Melihat Data Nilai Siswa Halaman Wali Kelas

\begin{tabular}{|l|l|}
\hline Use Case Name & Melihat Data Nilai Siswa \\
\hline Requiretments & B2 \\
\hline Goal & Wali Kelas dapat melihat nilai \\
\hline Pre-Conditions & Wali Kelas sudah login \\
\hline Post -Conditions & Data nilai terlihat \\
\hline $\begin{array}{l}\text { Failed end } \\
\text { Condition }\end{array}$ & Gagal melihat nilai \\
\hline Primary Actors & Wali Kelas \\
\hline Main Flow / Basic & $\begin{array}{l}\text { 1. Wali Kelas memilih menu } \\
\text { nilai }\end{array}$ \\
Path & 2. Sistem menampilkan nilai \\
& 3. Wali Kelas dapat melihat nilai \\
\hline
\end{tabular}




\section{c. Usecase Diagram halaman Guru}

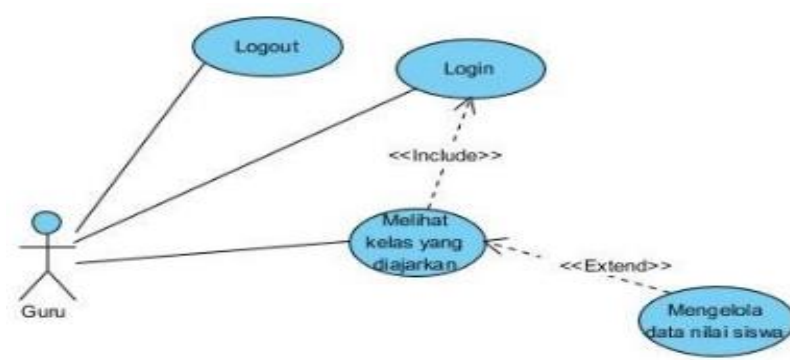

Gambar IV.3. Use Case Diagram Halaman Guru

Tabel IV.3.

Deskripsi Use Case Mengelola Data Nilai Siswa Halaman Guru

\begin{tabular}{|c|c|}
\hline Use Case Name & Mengelola Nilai Siswa \\
\hline Requirements & $\mathrm{C} 3$ \\
\hline Goal & $\begin{array}{l}\text { Guru dapat menginput, merubah, } \\
\text { atau menghapus nilai siswa ( } \\
\text { ulangan harian, tugas, nilai tengah } \\
\text { semester dan nilai uas ) }\end{array}$ \\
\hline Pre-Conditions & Guru telah melakukan login \\
\hline Post-Conditions & $\begin{array}{l}\text { Sistem akan menampilkan pilihan } \\
\text { untuk menambahkan atau } \\
\text { mengganti nilai siswa }\end{array}$ \\
\hline $\begin{array}{l}\text { Failed end } \\
\text { Conditions }\end{array}$ & Gagal mengelola data nilai \\
\hline Primary Actors & Guru \\
\hline $\begin{array}{l}\text { Main Flow / Basic } \\
\text { Path }\end{array}$ & $\begin{array}{l}\text { 1. Guru memasukan username } \\
\text { dan password untuk } \\
\text { melakukan Login. } \\
\text { 2. Sistem menampilkan halaman } \\
\text { guru } \\
\text { 3. Guru memilih menu kelas } \\
\text { 4. Sistem akan menampilkan } \\
\text { menu nilai } \\
\text { 5. Guru memilih jenis nilai yang } \\
\text { ingin diberikan. Kemudian } \\
\text { guru memasukan nilai yang } \\
\text { sesuai. } \\
\text { 6. Guru memilih menu simpan } \\
\text { nilai, maka nilai akan } \\
\text { langsung tersimpan }\end{array}$ \\
\hline
\end{tabular}

\section{d. Use Case Diagram Halaman Administrator}

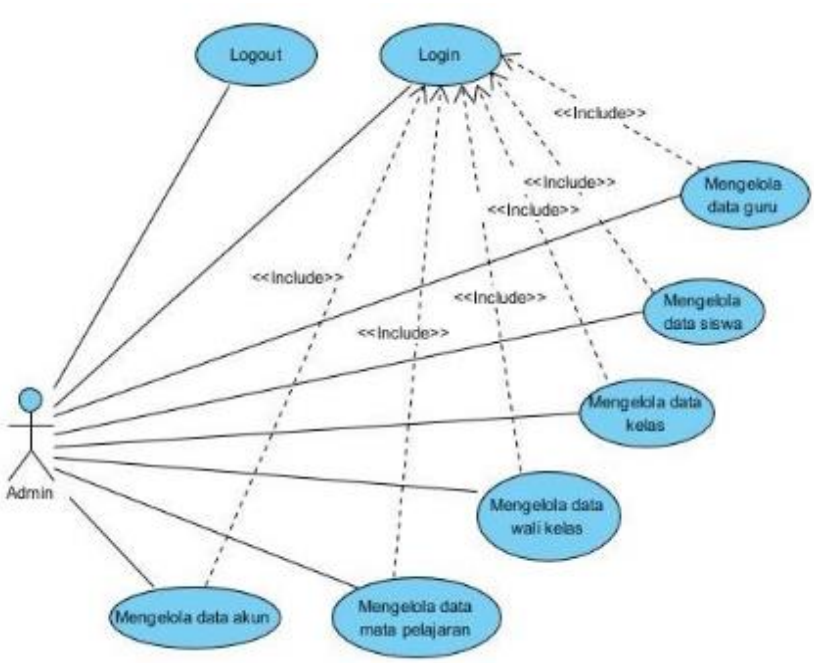

Gambar IV.4. Use Case Diagram Halaman Administrator

Tabel IV.4.

Deskripsi Use Case Mengolah Data Guru Halaman Administrator

\begin{tabular}{|l|l|}
\hline Use Case Name & Mengelola Data Guru \\
\hline Requiretments & D2 \\
\hline Goal & $\begin{array}{l}\text { Admin dapat menambah dan } \\
\text { menghapus data guru }\end{array}$ \\
\hline Pre-Conditions & Admin sudah login \\
\hline Post - Conditions & Data guru bertambah dan terhapus \\
\hline $\begin{array}{l}\text { Failed end } \\
\text { Condition }\end{array}$ & $\begin{array}{l}\text { Data guru gagal bertambah dan } \\
\text { gagal terhapus }\end{array}$ \\
\hline Primary Actors & Admin \\
\hline & $\begin{array}{l}\text { 1. Admin memilih menu Data } \\
\text { guru }\end{array}$ \\
& $\begin{array}{l}\text { 2. Sistem menampilkan data } \\
\text { guru }\end{array}$ \\
& $\begin{array}{l}\text { 3. Admin dapat menambah data } \\
\text { guru }\end{array}$ \\
Main Flow /Basic & $\begin{array}{l}\text { 4. Admin melakukan simpan } \\
\text { Path }\end{array}$ \\
& $\begin{array}{l}\text { 5. Sistem menyimpan data yang } \\
\text { telah ditambah }\end{array}$ \\
& $\begin{array}{l}\text { 6. Admin dapat menghapus data } \\
\text { guru }\end{array}$ \\
& 7. Sistem menghapus data guru \\
\hline
\end{tabular}


3. Activity Diagram

a. Activity Diagram Halaman Siswa

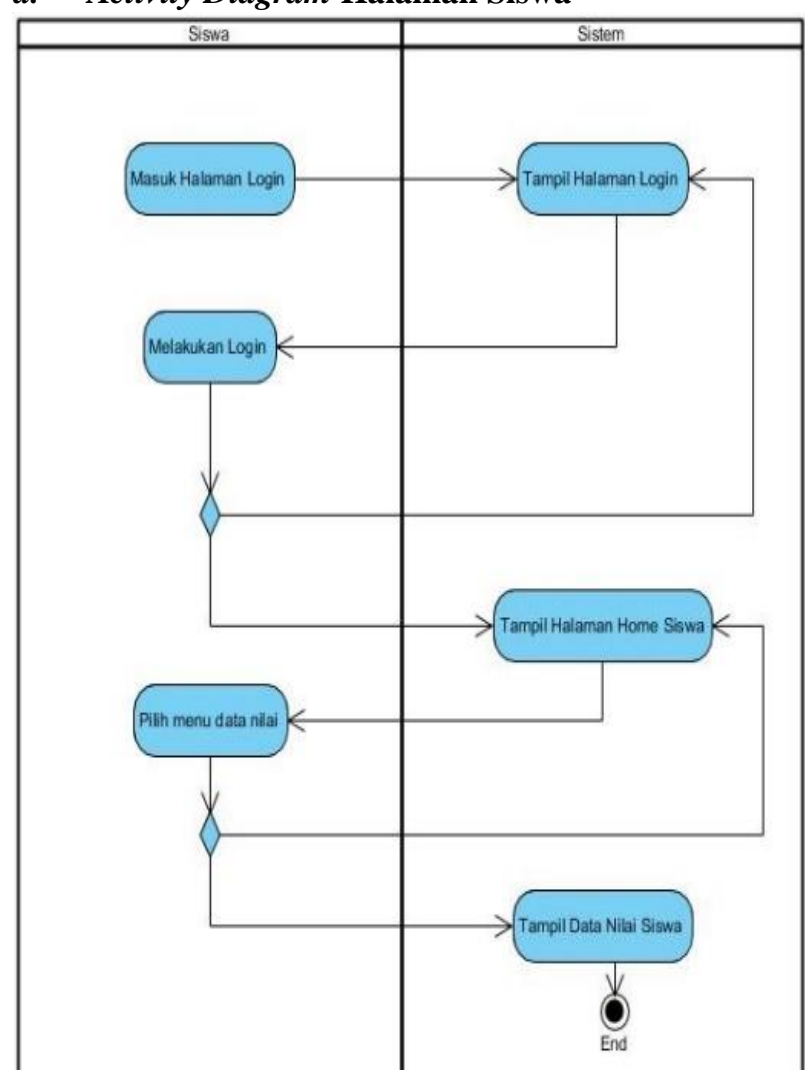

Gambar IV.5. Activity diagram Lihat Nilai Halaman Siswa

\section{b. Activity Diagram Halaman Wali Kelas}

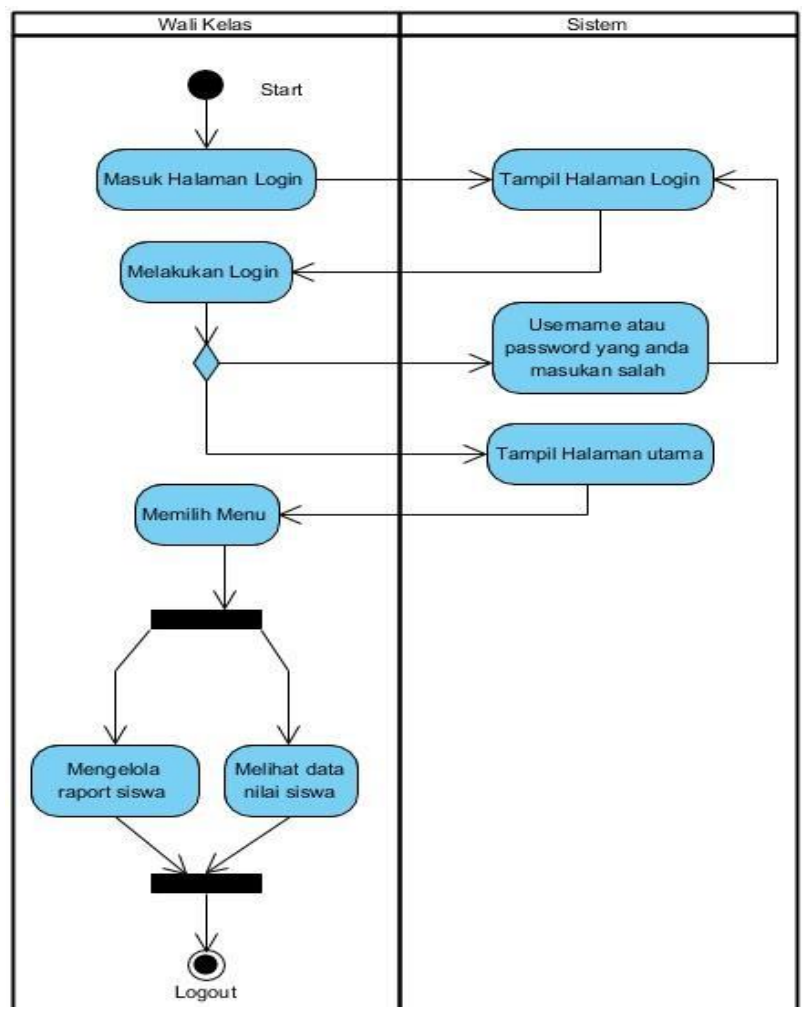

Gambar IV.6. Activity Diagram Halaman Wali Kelas

c. Activity Diagram Mengolah Data Siswa Halaman Admin

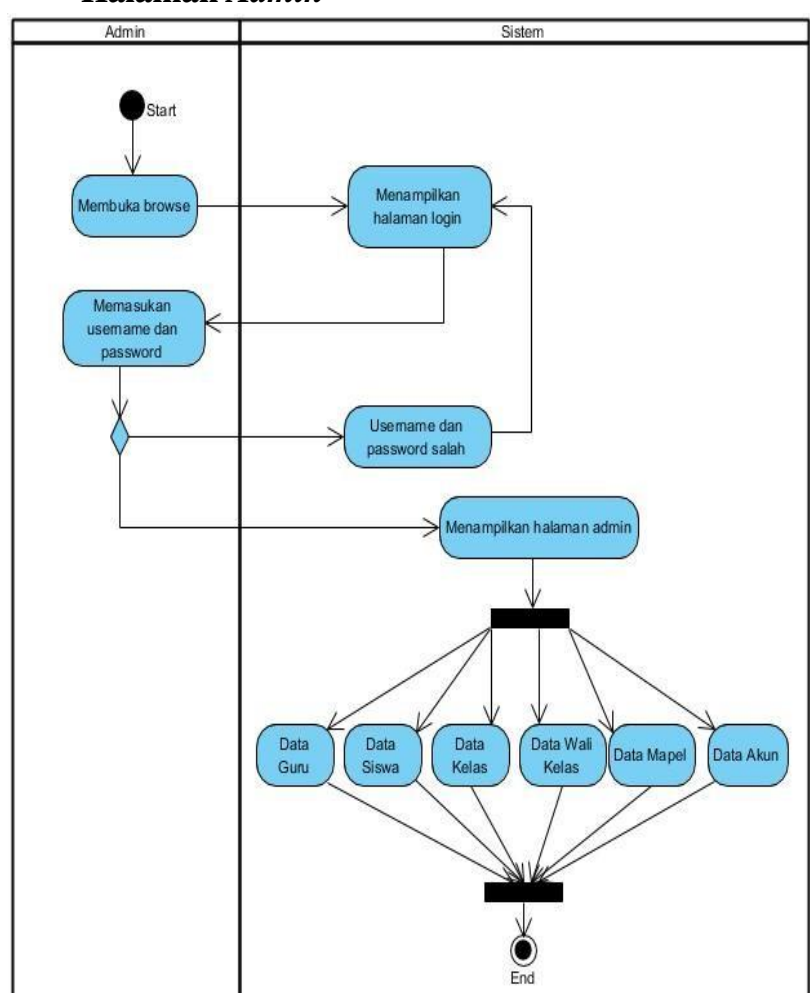

Gambar IV.7. Activity Diagram Mengolah Data Halaman Admin 
1. Desain Database

a. Entity Relationship Diagram

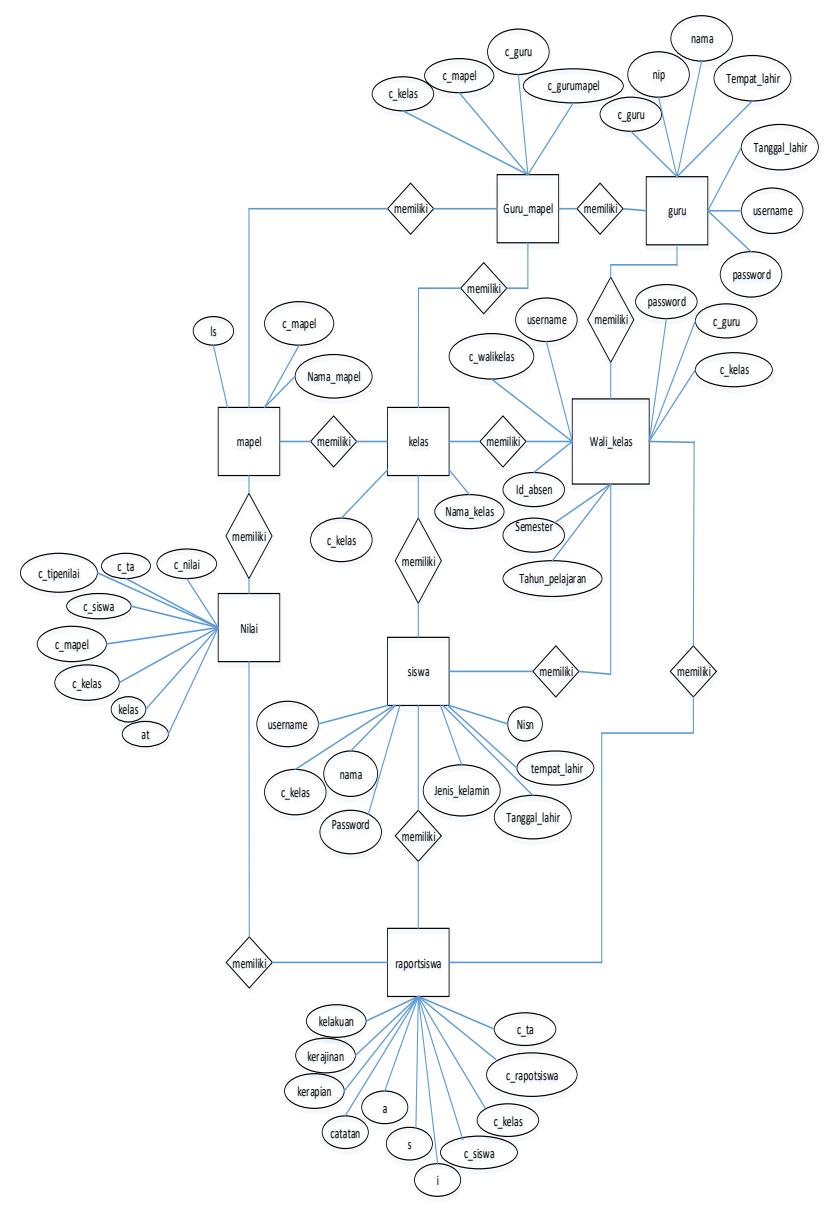

b. Logical Record Structure (LRS)

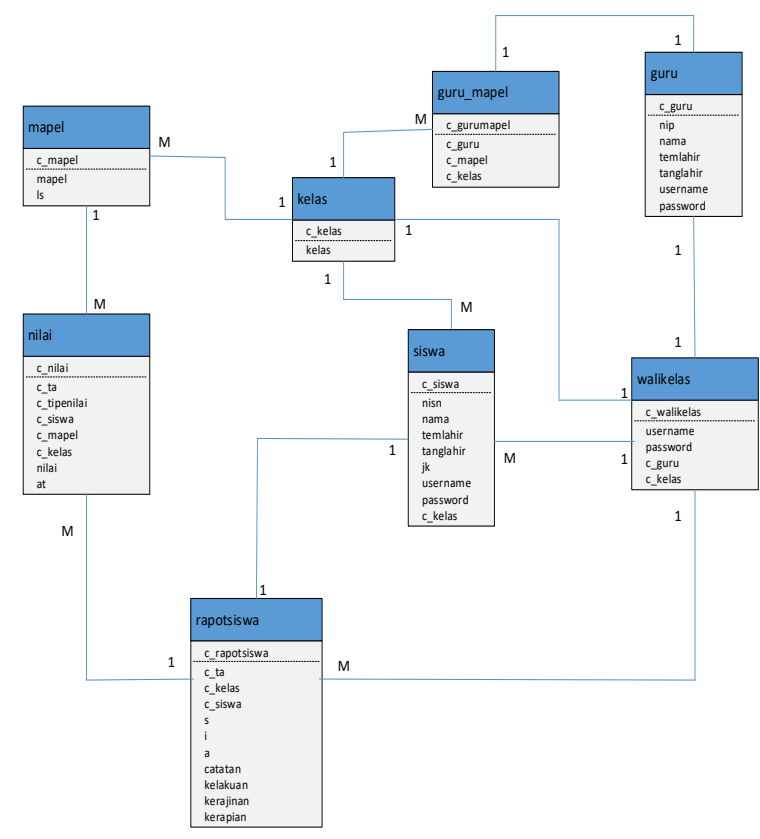

Gambar IV.9 Logical Record Structure

Gambar IV.8. Entity Relationship Diagram 
c. Rancangan Tampilan

1) Halaman Login

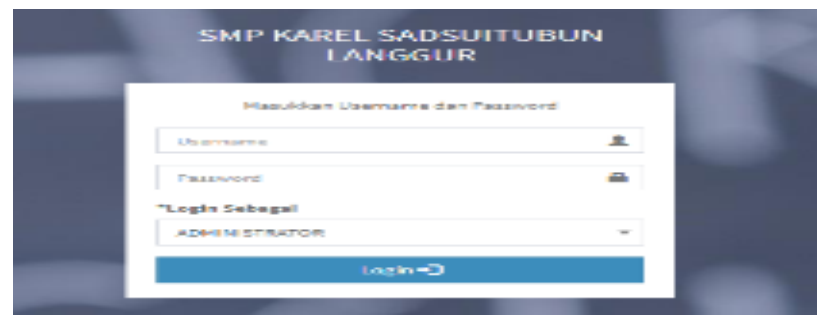

Gambar IV.10. Halaman Login

2) Halaman Input Data Admin

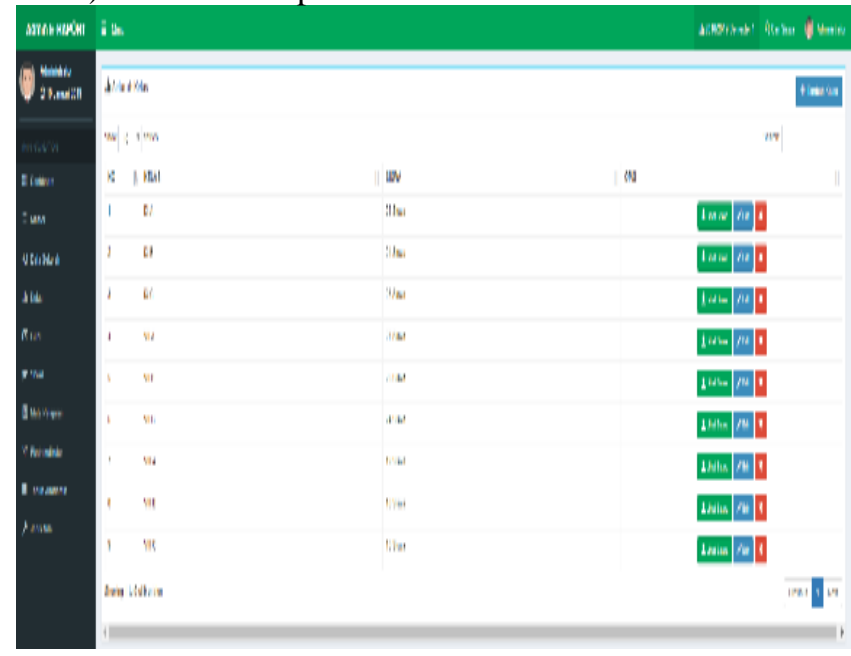

Gambar IV.11. Halaman Input Administrator

3) Halaman Wali Kelas

\begin{tabular}{|c|c|c|c|c|c|}
\hline minuref & Itis & & & & 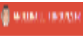 \\
\hline 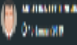 & 1. & & & & 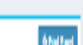 \\
\hline 1) & bo . . . the & & & & $\operatorname{lin} t$ \\
\hline I wiv & 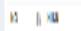 & $m$ & $\ln n$ & 17 & iN \\
\hline Amilizen & win & miven & $m$ & (xw & nowat \\
\hline & winn & 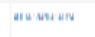 & wi. & $\cdots \cdots$ & Dans \\
\hline & mow & แ⿻ะหาพ & 10.6 & $\ln x+4=$ & mat \\
\hline & "w:III & 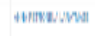 & $1 m$ & I W HWX & bymat \\
\hline & wim & winke & wh & he 1 minhas & Intar \\
\hline & man & nw: м.а & It.it & "ww we.". & trats \\
\hline & 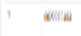 & mwoveli: & it.it & 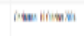 & Drow \\
\hline & Mntw & meinstwer & im & $\cot 1 \mathrm{w} x$ & Descater \\
\hline & mistax & Ша: & ind & umatimy & Bm \\
\hline & swue & Wwin: & in. & 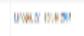 & Dowat \\
\hline & 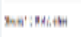 & & & & 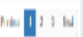 \\
\hline
\end{tabular}

Gambar IV. 12. Halaman Wali Kelas

\section{4) Halaman Nilai Siswa}

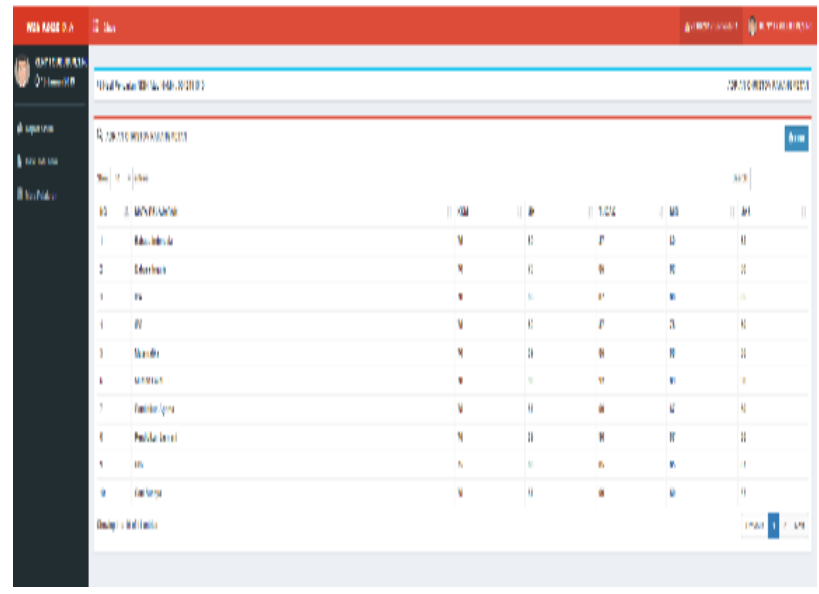

Gambar IV.13. Halaman Nilai Siswa

\section{5) Halaman Setting Raport}

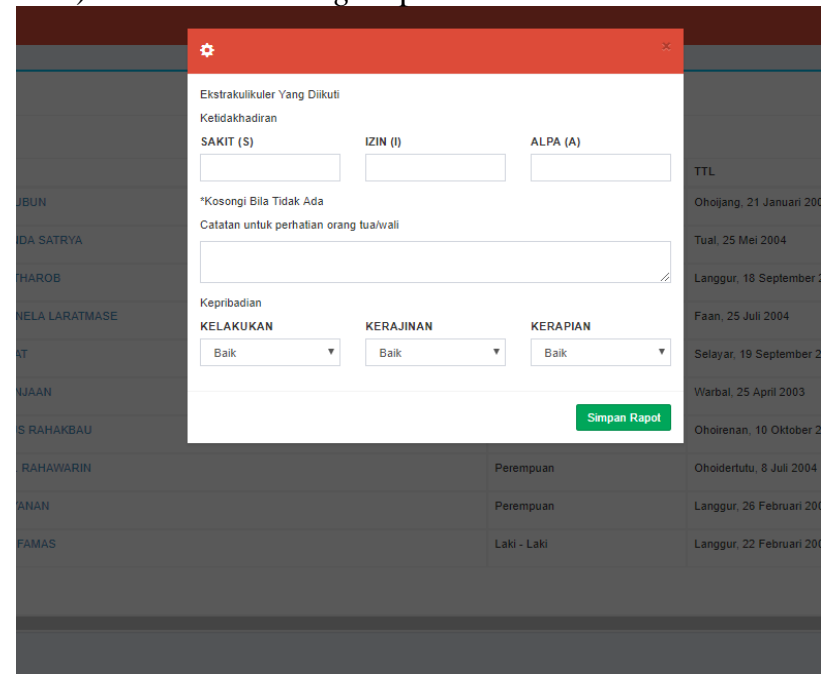

Gambar IV.14. Halaman Setting Raport

6) Halaman Guru

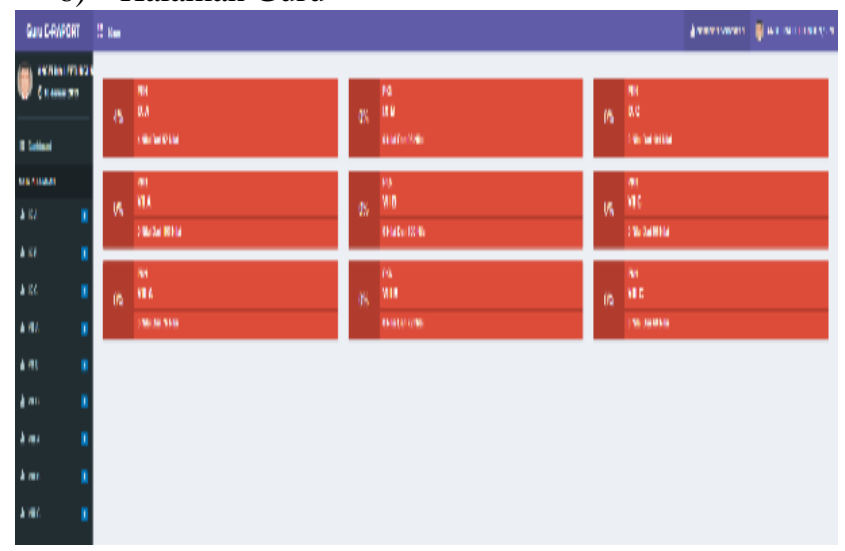

Gambar IV. 15. Halaman Guru 
7) Halaman Input Nilai

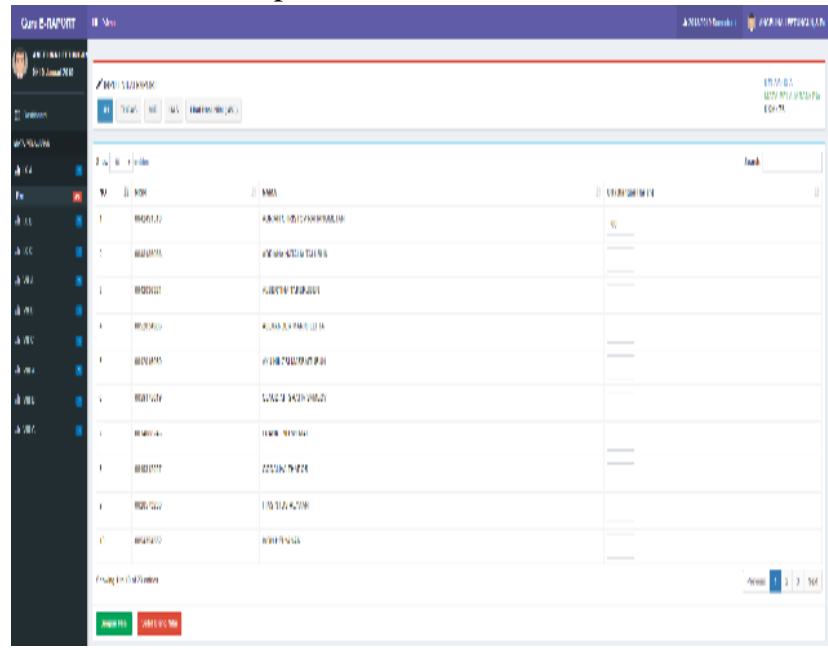

Gambar IV. 16. Halaman Input Nilai

8) Halaman Cetak Raport

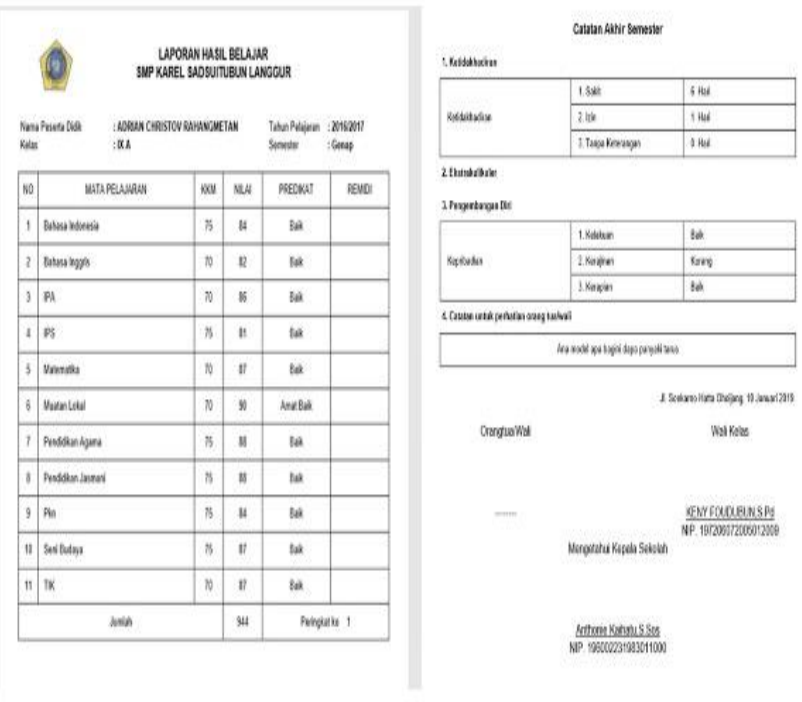

Gambar IV.17. Halaman Cetak Raport

\section{PENUTUP}

\section{a. Kesimpulan}

Dari hasil penulisan skripsi mengenai Sistem Informasi Pengolahan Data Nilai Berbasis Web pada SMP Karel Sadsuitubun Langgur ini, penulis dapat mengambil kesimpulan mengenai perancangan sistem informasi ini sebagai berikut:

1. Sistem informasi yang dibangun ini akan berbasis web sehingga diharapkan dapat membantu guru, siswa, serta orang tua untuk mengakses informasi data nilai melalui internet

2. Sistem informasi pengolahan data nilai berbasis web ini dibangun dengan memiliki hak akses, yaitu admin dan user. Siswa dan guru sebagai user dapat mengakses informasi data nilai secara online melalui media browser internet.

3. Dengan adanya Sistem Informasi Pengolahan Data Nilai pada SMP Karel Sadsuitubun Langgur ini, diharapkan dapat mempermudah kinerja guru khususnya wali kelas dalam mencetak raport siswa.

\section{b. Saran-saran}

Pada Sistem Informasi Pengolahan Data Nilai Berbasis Web pada SMP Karel Sadsuitubun Langgur ini penulis sadar bahwa masih terdapat keterbatasan, sehingga memerlukan saran yang dapat membantu dalam proses pengembangan kedepannya. Berikut ini merupakan saran yang penulis berikan :

1. Sistem informasi data nilai ini sebaiknya dikembangkan agar tidak hanya wali kelas yang dapat mencetak data nilai siswa, tetapi juga bisa dicetak langsung oleh para siswa.

2. Website ini disarankan agar dapat dikembangkan lebih jauh lagi agar tidak hanya terbatas pada proses pengolahan data nilai siswa, tetapi juga dapat digunakan untuk informasi akademik lainnya tentang SMP Karel Sadsuitubun Langgur.

3. Perlu adanya backup data karena semakin banyaknya data akan memperlambat kinerja sistem.

\section{Daftar Pustaka}

Alpiandi, R.M. (2016). Sistem Informasi Akademik Berbasis Web Di SMP Negeri 2 Kecamatan Gaung Anak Serka. Jurnal SISTEMASI, 5(3), 813

Djaelangkara, R. T, Sengkey. R, Lantang, O. A (2015) Perancangan Sistem Informasi Akademik Sekolah Berbasis Web Studi Kasus Sekolah Menengah Atas Kristen 1 Tomohon. E-jurnal Teknik Elektro dan Komputer, ISSN:2301-8402

Hidayatullah, P., \& Kawistara, J. K. (2015). PEMROGRAMAN WEB. Pemrograman Web (kedua). Bandung: Informatika Bandung.

Jupriyono,J, S Sriyadi. (2018). SISTEM INFORMASI AKADEMIK BERBASIS WEB PADA SMP TAHFIDZ AL-AMIEN PRENDUAN. Jurnal Sistem Informasi ,4 (1), 81-89.

Kesuma, C., \& Rahmawati, L. (2015). Sistem Informasi Akademik Berbasis Web Pada Smk AlMiftahiyyah, $I V(2), 142-150$.

Madcoms. (2016). Sukses Membangun Toko Online dengan PHP \& MySQL. Yogyakarta: Andi.

Membara, Eko Putra Membara, Liza Yulianti \& Indra Kanedi (2014). SISTEM INFORMASI 
AKADEMIK SMP NEGERI 2 TALANG EMPAT BERBASIS WEB. Jurnal Media Infotama, 10(1), 72-80.

Nugraha, Tezhar Rayendra Trastaronny Pastika, Wing Wahyu Winaryo \& Hanif Al Fatta (2018). ANALISIS SISTEM INFORMASI AKADEMIK MENGGUNAKAN DOMAIN DELIVERY AND SUPPORT COBIT 5 PADA SMKN 4 YOGYAKARTA. Jurnal Ilmiah d'Computare, Vol 8 , 21-29.

Pahlevi, Said Mirza. (2013). Tujuh Langkah Praktis Pembangunan Basis Data Jakarta : PT Elex Media Komputindo.

Pratama. (2014). SISTEM INFORMASI dan IMPLEMENTASINYA. (Pratama, Ed.) (1st ed.). Bandung: Informatika Bandung.

Prayitno,A. Y. S. (2015). Pemanfaatan Sistem Informasi Perpustakaan Digital Berbasis Website Untuk Para Penulis. IJSE - Indonesian Journal on Software Engineering, 1(1), 1-10. Retrieved from Lppm3.bsi.ac.id/jurnal

Priyadi, Y. (2014). Kolaborasi SQL \& ERD Dalam Implementasi Database. (Maya, Ed.) (1st ed.). Yogyakarta: ANDI.

Purnama, V. C., \& Hasan, N. (2016). Perancangan
Sistem Informasi Inventori Darah Berbasis Web Pada Palang Merah Indonesia Cabang Bantul. Journal Speed - Sentra Penelitian Engineering dan Edukasi , 8(3), 35-41.

Sarsaswati, E. (2013). Sistem Informasi Akademik Berbasis Web Pada Sekolah Menengah Pertama (Smp) Negeri 3 Pringkuku. IJNS - Indonesian Journal on Networking and Security, 2(4), 34-39.

Sudradjat, Budi (2018). RANCANG BANGUN SISTEM INFORMASI PENJUALAN FASHION BERBASIS WEB. Jurnal Interkom, 13(3), 22-28.

Sukamto, R., \& Salahuddin, M. (2014). REKAYASA PERANGKAT LUNAK (2nd ed.). Bandung: Informatika Bandung.

Sumarlinda, Sri (2017). RANCANG BANGUN SISTEM INFORMASI NILAI SISWA PADA MADRASAH IBTIDAIYAH ISLAMIYAH NGREJENG KABUPATEN BOJONEGORO. Jurnal INFORMA Politeknik Indonusa Surakarta, 1(3), 37-51.

Wardani, S. K. (2013). Sistem Informasi Pengolahan Data Nilai Siswa Berbasis Web Pada Sekolah Menengah Atas (Sma) Muhammadiyah Pacitan. Indonesian Jurnal on Networking and Security, 2(2), 30-37. 